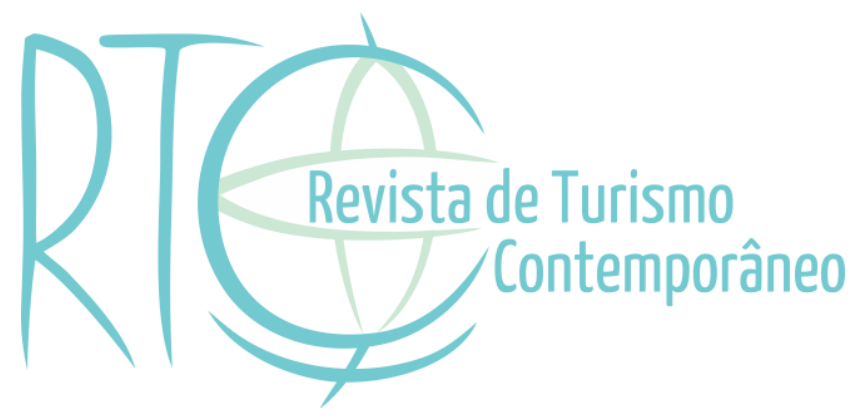

\title{
Um estudo da influência da cozinha internacional sobre a cozinha regional de Canoa Quebrada - CE
}

\section{A study of the influence of international cuisine on the regional cuisine of Canoa Quebrada - CE}

Eveline Porto Sales Aguiar

Professora efetiva do Instituto Federal do Ceará- IFCE, Aracati/CE, Brasil

E-mail: evelineps@gmail.com

Stella Maria Carvalho de Melo

Professora do curso de Secretariado do Instituto Federal do Piauí - IFPI, Teresina/PI, Brasil

E-mail: stella@ifpi.edu.br 


\section{RESUMO}

Este artigo teve como objetivo analisar como a cozinha regional está presente nos cardápios dos restaurantes internacionais da praia de Canoa Quebrada - CE, unindo elementos da gastronomia local em pratos de características internacionais. É uma praia internacionalmente conhecida, com hotéis e restaurantes internacionais. Esta pesquisa é exploratória, descritiva, explicativa e aplicada, tratando-se de um estudo teórico e prático, com técnica de tratamento qualitativa e estratégia de pesquisa por meio de estudos de casos múltiplos. No campo, foram pesquisados cinco restaurantes: Restaurante A - cozinha mediterrânea (mescla entre a comida espanhola e a italiana); Restaurante B - cozinha espanhola; Restaurante C - cozinha portuguesa; Restaurante D - cozinha francesa e italiana e Restaurante E - cozinha italiana. Os restaurantes selecionados deveriam atender aos seguintes critérios: serem restaurantes étnicos; possuírem serviço à la carte; e estarem catalogados como opção de restaurante no website TripAdvisor (2014). A coleta de dados foi feita por meio da realização de entrevista estruturada com os chefs de cozinha e proprietários, com finalidade exploratória e de conhecimento e registro fotográfico do cardápio. Como resultados, observou-se a utilização de ingredientes regionais na composição de pratos internacionais, como leite de coco, coentro, cheiro verde e pimenta, sem, contudo, descaracterizá-los. Assim, o resultado da pesquisa apontou que os ingredientes utilizados nas preparações dos restaurantes internacionais em Canoa Quebrada são semelhantes aos mesmos utilizados na cozinha brasileira, regional e local, diferenciando-se o modo de preparo e a nomenclatura dos pratos.

Palavras-chave: Cozinha. Gastronomia. Restaurantes. Cardápio.

\section{ABSTRACT}

This article aims to analyze how regional cuisine is present in the menus of international restaurants on the beach of Canoa Quebrada - CE, combining elements of local cuisine in dishes of international features. It is a beach internationally known with hotels and international restaurants. This research is exploratory, descriptive, explanatory and applied, as well as a theoretical and practical study with a qualitative treatment technique and research strategy through multiple case studies. In the field, we searched five restaurants: The Restaurant A - Mediterranean cuisine (mixed between Spanish and Italian food); Restaurant B - Spanish cuisine; Restaurant C - Portuguese cuisine; Restaurant D - French and Italian cuisine and Restaurant E - Italian cuisine. The selected restaurants should meet the following criteria: to be international restaurants; to offer a la carte service; and to be categorized as restaurant option on the TripAdvisor website (2014). Data collection was carried out by conducting structured interviews with chefs and owners, with exploratory and knowledge purposes and photographic record of the menu. Therefore, the result indicated that the ingredients used in the food preparation of the international restaurants in Canoa Quebrada are similar to the ones used in Brazilian cuisine, at regional and local levels, but with a different method of preparation and different dishes' names.

Keywords: Kitchen. Gastronomy. Restaurants. Menu. 


\section{INTRODUÇÃO}

O turismo é uma atividade que envolve diversos setores econômicos, e um deles é o setor da alimentação, pois uma pessoa, quando viaja, independente do motivo, entra em contato com a gastronomia local. Esta faz parte do costume de seu povo, revelando não só aspectos da sua geografia, como também suas particularidades humanas, econômicas, sociais e culturais.

Conforme Schlüter (2003, p. 11) "a cozinha tradicional está sendo reconhecida cada vez mais como um componente valioso do patrimônio intangível dos povos”. Ou seja, a comida tem um valor que vai além do que o comensal come, vai desde a sua preparação e significado para cada sociedade, fortalecendo aspectos fundamentais da cultura local.

Sendo a gastronomia um recurso cultural e uma experiência gastronômica, a Canadian Tourism Commission (2002, p. 1) menciona que "gastronomia e cozinha são elementos a adicionar à experiência turística cultural".

Deste modo, os restaurantes representam espaços onde a gastronomia ganha visibilidade, sendo, assim, lugares de representação social, oferecendo ambientes de descontração, lazer, manifestação de status social e que essencialmente devem proporcionar a satisfação das necessidades fisiológicas e o prazer intrínseco de comer.

A gastronomia, ao longo dos anos, foi ganhando características diferentes, de acordo com o local onde era desenvolvida, bem como a sua história ia sendo construída. Por isso, surgiram os diversos tipos de cozinha, que neste artigo optou-se por destacar: a cozinha regional e a cozinha internacional

Para Franco (2004, p. 257) a cozinha internacional consiste em "um conjunto de técnicas e princípios que permitem adaptação às possibilidades locais. É internacional graças ao talento de chefs que, dominando os fundamentos da cozinha clássica e usando de flexibilidade, podem reinterpretar receitas de diferentes origens". Assim, a cozinha internacional atrai os comensais pela curiosidade em conhecer outra cultura, a partir da degustação da comida e do contato com os costumes apresentados nesses restaurantes.

Em se tratando de cozinha regional, Bahl, Gimenes e Nitsche (2011) reportam-se ao Brasil como um país dotado de uma multiplicidade de cozinhas regionais, estabelecidas por meio da influência do homem no meio e dos fluxos migratórios, internos e externos. Com isso, tem-se como resultado uma gastronomia diversificada, tanto a nível dos ingredientes (peixes, frutas e verduras) como das técnicas de preparo, serviços e ritualística relacionada. 
Por esse motivo, a cozinha regional compõe a oferta turística e leva o turista a vivenciar costumes, técnicas e tradições da comida local.

Por consequência, a cozinha regional relaciona-se com a história, a geografia do lugar e com uma maior facilidade na busca pelos ingredientes, sendo mais sustentável econômica, ambiental e socialmente, devido à agilidade da rede de fornecedores locais para aquisição dos ingredientes básicos (Murta, Souza \& Carrieri, 2010).

Isto vem acontecendo na cidade de Aracati-CE, mais precisamente na Praia de Canoa Quebrada, um destino turístico bastante procurado no litoral do Ceará, que atrai turistas de diversas localidades, especialmente os turistas estrangeiros, que vão em busca, principalmente, do turismo de sol e praia. Vale salientar que, no ano de 2014 , dentre os principais municípios visitados do Ceará pelos turistas que ingressaram via Fortaleza, registrou-se Aracati como o terceiro destino mais procurado, ficando atrás apenas de Aquiraz e Caucaia, provavelmente por serem mais próximos à capital. Em números, isto representa que, dos 2.340.671 de turistas que ingressaram em Fortaleza, motivados por lazer/passeios; visitas a parentes/amigos; negócios/trabalho; congressos/eventos, tem-se um total de 314.564 turistas que visitaram Aracati, sobretudo Canoa Quebrada, permanecendo ali, em média, 5,10 dias (Ceará, 2016).

A pesquisa aponta a média de permanência de 5 dias, bastante razoável para conhecer o que o Município pode oferecer, tanto em termos de patrimônio natural quanto cultural, a exemplo, conhecer a Rua Coronel Alexanzito, mais conhecida como Rua Grande, lugar que reúne um conjunto de casarões e sobrados, dotados com azulejos originalmente portugueses, tombados pelo Instituto do Patrimônio Histórico e Artístico Nacional - IPHAN, e reconhecido como Patrimônio Nacional (Galvão, 2006).

Estes turistas, ao chegarem à localidade, entram em contato com a cozinha local, gerando empregos e renda no setor de Alimentos e Bebidas. Assim, o foco deste trabalho foi analisar como a cozinha regional está presente nos cardápios dos restaurantes da praia de Canoa Quebrada, unindo elementos da gastronomia local em pratos de características internacionais. Esta pesquisa faz parte de um estudo mais amplo, abordado em dissertação de mestrado, defendido por uma das autoras. 


\section{METODOLOGIA}

Esta investigação proporciona relevância para a área gastronômica do município de Aracati, com foco em um de seus principais destinos turísticos- a praia de Canoa Quebrada, com abordagem na cozinha internacional exercida na localidade, considerando-se a composição dos cardápios.

O trabalho foi feito com restaurantes de categoria comercial, classificados como restaurantes de especialidade, que por sua vez delimita-se aos restaurantes internacionais com serviço à la carte, que oferecem à sua clientela comidas típicas de uma cultura diferente da praia de Canoa Quebrada, atraindo diferentes tipos de comensais.

Em relação à metodologia, esta pesquisa teve caráter exploratório, descritivoexplicativo e aplicado, tratando-se de um estudo teórico e prático, com técnica de tratamento qualitativa e estratégia de pesquisa por meio de estudos de casos múltiplos.

De acordo com Dencker (1998), as pesquisas exploratórias compreendem, além do levantamento das fontes secundárias, o estudo de casos selecionados e a observação informal, e as pesquisas descritivas descrevem situações de mercado a partir de dados primários, que podem ser quantitativos ou qualitativos. Ainda para a autora, "são estudos bem estruturados e planejados que exigem conhecimento profundo do problema estudado por parte do pesquisador" (Dencker, 1998, p. 157). Para Lakatos e Marconi (2008), o estudo de caso refere-se ao levantamento, com mais profundidade, de determinada situação sob todos os seus aspectos.

Para a coleta de dados, foram utilizadas fontes primárias e secundárias. A pesquisa em fontes primárias fundamentou-se em documentos originais, coletados pela primeira vez pelas pesquisadoras, por meio de entrevistas, questionários e observação in loco, compreendendo o período inicial de maio de 2014 a março de 2015.

A coleta de dados teve início com a escolha dos restaurantes, os quais deveriam atender aos seguintes critérios, traçados em função das necessidades e especificidades da pesquisa, visando atender aos objetivos: serem restaurantes internacionais; possuírem serviço à la carte; e estarem catalogados como opção de restaurante no website TripAdvisor (2014), localizados na rua principal Broadway e Rua Nascer do Sol de Canoa Quebrada. Dessa maneira, foram pesquisados cinco restaurantes, correspondendo a uma amostra de $100 \%$ deste universo, conforme os critérios anteriormente citados.

Os restaurantes foram selecionados no período de outubro de 2014, atendendo aos critérios referidos, sendo eles: Restaurante A - cozinha mediterrânea com destaque para a 
comida espanhola; Restaurante B - cozinha espanhola; Restaurante C - cozinha portuguesa; localizados na Broadway; além do Restaurante D - cozinha francesa e italiana - e Restaurante E - cozinha italiana, localizados em rua paralela à Broadway - Rua Nascer do Sol. Não há registros de restaurantes representando especificamente a cozinha brasileira na Broadway, em Canoa Quebrada.

As visitas aconteceram no período compreendido entre outubro de 2014 e março de 2015. A fase de pesquisa de campo foi organizada em duas etapas:

$1^{\text {a }}$ Etapa: a coleta de dados aconteceu por meio da realização de entrevista estruturada com chefs de cozinhas e proprietários dos restaurantes, com finalidade exploratória e de conhecimento, que teve como foco a contextualização da origem e histórico dos restaurantes e, também, o conhecimento sobre as preparações dos cardápios. A entrevista foi realizada com o consentimento livre e esclarecido dos sujeitos, que manifestaram a sua anuência em participar da pesquisa, com a assinatura de um Termo de Consentimento Livre e Esclarecido, o qual foi elaborado em duas vias, sendo uma retida pelo sujeito da pesquisa e uma arquivada pelo pesquisador.

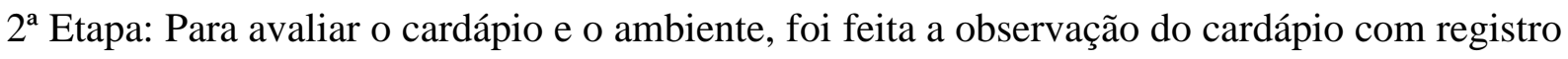
fotográfico por meio de fotos de aparelho smartphone, que permitem obter informação de modo econômico e confiável (Mendonça, Barbosa \& Durão, 2007). Levando-se em consideração apenas os pratos principais da casa, foram identificados os ingredientes dos pratos do cardápio com características da cozinha internacional e regional do Ceará, sob o enfoque da adaptação às possibilidades regionais.

\section{GASTRONOMIA, RESTAURANTES E CARDÁPIO}

A alimentação é uma necessidade fundamental para a sobrevivência da espécie humana, e desde o princípio ela é um ato de união e partilhamento, fazendo parte do convívio familiar como uma marca nas relações entre seus membros. Afinal, a alimentação está presente nos almoços em família, na ceia de natal, nos hábitos alimentares e, principalmente, quando há uma comemoração, reunião ou evento, ocasiões em que é possível perceber as pessoas reunidas ao redor de uma mesa, compartilhando o alimento.

Dentro do setor de alimentação, existem dois termos bastante utilizados: cozinha e culinária, que se constituem de palavras sinônimas, referindo-se ao conjunto de utensílios, ingredientes e pratos típicos de um país ou de uma região. Assim, cozinha e culinária denotam a arte de preparar as iguarias e os métodos e técnicas empregadas para esta finalidade (Freixa \& Chaves, 2012). 
A cozinha institui-se da manifestação da vida social, como forma de comunhão, de partilhar a comida e de revelar os costumes e crenças de um povo. A exemplo disso, tem-se como costume o uso de condimentos ou ingredientes como elemento diferenciador na elaboração de pratos, caracterizando-os como de uma região ou de outra, como o caldo verde de Portugal, que tem como ingredientes principais a couve portuguesa e o chouriço de carne, embora no Brasil se utilize comumente a calabresa.

Em uma cozinha, além dos ingredientes utilizados, evidenciam-se formas de condimentação, processos culinários, conjunto de normas, habilidades e técnicas, além dos aspectos culturais e higiênicos que devem fazer parte da produção de alimentos como fatores de promoção da saúde.

E é a cozinha um lugar singular de expressões simbólicas, satisfação das necessidades, consumação de desejos e realizações de um grupo social, bem como o lugar dos sonhos permanentes, das relações entre espaços, sujeitos, objetos e atividades (Arana, 2012).

Neste contexto, destaca-se, também, o vocábulo gastronomia com uma definição mais ampla, e a cozinha contida em uma das partes da gastronomia, referindo-se ao ato da cocção, que quer dizer cozinhar. A gastronomia consiste também na prática de conhecimento de outra cultura, de convívio com pessoas e lugares com um forte sentido da sua própria identidade (Santisch, 2004).

E para cozinhar, é preciso que existam as receitas culinárias, que reúnem instruções para a execução de determinados pratos, constituindo-se de ensinos que visam fundamentalmente o benefício do executor (Casanova, 1996). Portanto, a cozinha, na sua singeleza e mistério, conduz o homem a uma experiência de criatividade, inventividade e transformação do alimento.

Na compreensão de que o homem aprendeu a cultivar o alimento, caçar, pescar, e com o uso do fogo passou a cozinhá-lo, surgindo a cozinha propriamente dita e as técnicas de conceder sabores do seu estado cru para o cozido, é que então o mundo passa a conceber a gastronomia como parte da história de um povo, despertando sensações e inspirando a vontade e o desejo por novas percepções culinárias, integrando alimentos, cozinha, receitas e sabores.

Desta forma, entende-se a gastronomia como o somatório de história, cultura, arte e religião, por fazer parte de diferentes etapas da história do povo e do mundo. Falar em gastronomia é notoriamente refletir sobre a história da humanidade, em que as receitas e as formas de preparo são traços da cultura. 
Conforme Freixa e Chaves (2012, p. 20), “a gastronomia também está ligada às técnicas de cocção e ao preparo dos alimentos, ao serviço, às maneiras à mesa e ao ritual da refeição". A cozinha está inserida na gastronomia, sendo o alimento e a cozinha precedentes à gastronomia.

Compreende-se a gastronomia como um hábito alimentar de uma nação, a qual satisfaz as necessidades básicas do ser humano, como o ato de saciar a fome. Entretanto, a gastronomia também se relaciona ao costume de preparar alimentos vinculando-se à cultura e religiosidade, à localização geográfica, à etnia e à classe social.

Sendo assim, para Reinhardt (2002, p. 8), "através do alimento podemos identificar uma sociedade, uma cultura, uma religião, um estilo de vida, uma classe social, um acontecimento ou uma época". Percebe-se, então, que a gastronomia não é simplesmente a receita e o seu modo de execução, mas os valores históricos e culturais presente no prato, podendo, desse modo, descrever a história de qualquer povo falando de gastronomia.

É peculiar observar em vários estados brasileiros a predominância de alimentos que identificam as culturas. No Nordeste, são comuns os frutos do mar e os peixes; a farinha de mandioca, que faz a tapioca ou beiju; os doces em compotas; os alimentos à base de milho, como canjica, pamonha, bolo de milho, mungunzá; macaxeira, carne do sol entre outros. Cada alimento pode facilmente identificar uma região do país, seus costumes e tradições.

Antigamente, as pessoas costumavam fazer suas refeições apenas em casa. Com o tempo, foram surgindo espaços criados especialmente para isto: os restaurantes, onde as pessoas saíam de suas casas para desfrutar de pratos especiais em um ambiente diferenciado.

Os restaurantes constituem-se de espaços para as práticas gastronômicas, reunindo pessoas para saciar a fome e consequentemente proporcionar sensações agradáveis ao comensal. Eles surgiram na segunda metade do século XVIII, há 250 anos, e são relativamente recentes, frutos do capitalismo e do desenvolvimento da tecnologia (Castelli, 2003).

Assim, pelo senso comum, o restaurante é um lugar com a finalidade de saciar a fome e inserir o homem como um ser social em vivências com diversas pessoas. Dessa maneira, antes do século XIX, o termo restaurant (traduzido para a língua portuguesa como restaurante) remetia a um caldo regenerativo, com o objetivo de "restaurar as forças", por meio de um consomée (um caldo ralo, temperado com pedras preciosas, se o médico recomendasse), o que durou até o início do século XIX, quando o "restaurant" surgiu como sendo um espaço social urbano (Spang, 2003).

Os meios de restauração, agregados às suas tipologias, são espaços que representam lugares de descontração, lazer, entretenimento e prazer. Do século XVIII até os dias da Revista de Turismo Contemporâneo-RTC, Natal, v. 6, n. 1, p. 151-170, jan./jun. 2018. 158 
contemporaneidade, pode-se encontrar diversos tipos de restaurantes para atender aos públicos mais exigentes e seletivos.

Desta forma, os restaurantes são estabelecimentos que fornecem alimentação mediante pagamento e englobam os mais variados tipos, como pizzarias, restaurantes regionais, churrascarias, restaurantes de hotel, restaurantes clássicos, entre outros (Pacheco, 2005).

Essa pesquisa está focada nos restaurantes internacionais. Este termo é uma forma muito usual de referir-se à cozinha típica de países como Itália, França, Portugal e outros (Montebello \& Collaço, 2007). Os restaurantes internacionais destacam-se pela diferenciação na comida elaborada e servida, pelos ingredientes utilizados e por tratar-se de uma cozinha de um determinado país, comumente encontrados a etnia francesa, espanhola e italiana.

Dentro de um restaurante, o cardápio é seu instrumento de vendas e deve conceber o tipo do restaurante, pois deve-se levar em consideração as características do ambiente, a decoração, o tipo de cozinha a ser montada, a matéria-prima a ser utilizada e até mesmo a mão de obra a ser recrutada.

Com base nisso, um dos primeiros contatos do cliente com a filosofia do restaurante consiste em conhecer a sua essência, o cardápio, o qual listará a ordem e relação das comidas preparadas no estabelecimento. Vasconcellos, Cavalcanti e Barbosa (2002, p. 22) visualizam o cardápio como “(...) o cartão de visitas do restaurante, praticamente o primeiro contato do cliente com a casa e responsável pela primeira impressão, boa ou má, que esse cliente vai desenvolver". Logo, o cardápio é um instrumento de marketing com a finalidade de atrair o seu público alvo.

O cardápio, se não for bem elaborado e planejado, pode correr o risco de não ser bem visto pelo olhar exigente do cliente. Se isso acontece, dificilmente ele retorna, todavia se o cardápio cumpre a função de despertar o apetite com os olhos, ele atingiu o seu objetivo e será bem agradável ao cliente, que imediatamente utiliza as redes sociais para divulgar um bom lugar para se comer e beber, pois para um bom cardápio pode ser que se tenha uma boa comida.

Vasconcellos, Cavalcanti e Barbosa (2002) mencionam que os cardápios devem conter uma descrição do que o cliente está solicitando, pois o mesmo pode ter alguma restrição alimentar.

Os sabores devem ser explicitados no cardápio, pois os mesmos podem ser: ácido, salgado, apimentado, azedo, amargo, doce, picante ou suave. Os temperos dão ao prato características definidas, podendo ser picante, apimentado, suave ou temperos que identificam 
determinadas cozinhas: orégano (cozinha italiana), hortelã (cozinha árabe), curry (cozinha asiática), mostarda (cozinha alemã).

Por fim, é de fundamental importância conhecer as preparações básicas e nomenclatura clássica, pois o responsável pela elaboração do cardápio deve conhecer os ingredientes utilizados nas preparações, para que saiba identificar ingredientes nas preparações.

Aspectos no planejamento do cardápio, como etnia e cultura, são fatores importantes para um restaurante de tipologia internacional. Neste caso, o cardápio deveria primar em conhecer o perfil do cliente e adaptar os pratos conforme as necessidades dos comensais.

Então, o planejamento de cardápio se faz necessário, uma vez que o empreendedor do mercado de alimentação precisa ser inovador e buscar o diferencial competitivo. Uma empresa bem organizada a partir do cardápio tem grandes chances de prosperar e ter sucesso, encantando e fidelizando os seus clientes.

\subsection{Contextualizando a Cozinha: Uma abordagem Internacional e Regional}

A cozinha internacional atrai os comensais motivados pela curiosidade em conhecer outra cultura, sendo envolvidos pela comida e costumes apresentados nesses restaurantes, destacando-se o uso de temperos, ervas e ingredientes distintos do seu país de origem.

A conhecida "cozinha internacional” tem raízes antigas, remontando-se às culinárias romana "mediterrânea" e medieval "europeia", as quais mantinham-se abertas à totalidade do mundo conhecido e frequentado. Assim, os ingredientes de origem estrangeira sempre foram bem requisitados, conhecidos como marca de prestígio social, porém na condição de que os "pratos" elaborados com base nos recursos locais sempre existiram (Montanari, 2008).

Todavia, a questão da comensalidade perpassa o ato de saborear um bom prato em um restaurante, tornando-se uma opção de lazer, onde o mercado de cozinha internacional está em franca expansão, principalmente devido à globalização, aos intercâmbios culturais, às divulgações das culturas do mundo, o que permite e facilita possibilidades de experimentar pratos típicos de várias regiões do mundo (Gerdes Filho \& Lopes, 2009).

Esse regionalismo depende da valorização da matéria prima local produzida e destinada à cozinha em foco. É muito presente as raízes locais e a tipicidade das comidas, o que as conferem características próprias dos diversos lugares.

Consequentemente produzir comidas típicas está imbuído de sabores e saberes do imaginário das pessoas, principalmente as pessoas com mais idade, concebendo receitas que são passadas de geração a geração. Onde cada região do Brasil tem receitas específicas e 
ingredientes muitas vezes encontrados somente in loco, assim como preferências e gostos diversos. São comidas que têm representatividade a exemplo do acarajé da Bahia, do pão de queijo de Minas Gerais, dos croquetes do Rio de Janeiro entre outros.

Logo, para que a cozinha regional se mantenha viva na memória das pessoas é necessário que os produtos típicos e a matéria prima original continuem sendo cultivados e ensinados para que não se perca o valor na história. É preciso manter os ingredientes, cultura e tradição.

Os tipos de pratos e de bebidas mudam de região para região, não somente os ingredientes, mas as técnicas de preparo, de cocção, a apresentação do prato, os utensílios utilizados, dentre outros aspectos.

O Brasil, por ser um país de grande extensão, com variação no clima, relevo e solos, bem como pelas diferenças de povoamento de suas diferentes regiões, tem uma cozinha diversificada, a qual se expressa, geograficamente, por meio dos "pratos típicos" regionais e acrescentando-se a diversidade estrangeira que compõe os pratos brasileiros (Botelho, 2012).

A cozinha regional pode ser compreendida conforme Bahl, Gimenes e Nitsche (2011, p. 2) como “(...) um conjunto de saberes-fazeres que engloba ingredientes, técnicas culinárias e receitas que são dispostas em um panorama relativamente coerente, delimitado geograficamente e passível de ser reconhecido como tal”. Assim, uma cozinha regional da França, é considerada para os brasileiros como cozinha internacional, devido às delimitações geográficas e culturais.

Dessa forma, os pratos típicos são considerados comidas simbólicas, inseridas na cozinha regional, representando um povo, tendo a gastronomia como a arte de cozinhar por meio do modo de preparação dos alimentos e a sua cocção; o comer bem destacando a beleza do prato, o deleite proporcionado pela comida, bebidas e especialmente atendimento e a cultura alimentar com os ingredientes e técnicas utilizadas (Kivela \& Crotts, 2006).

Deste modo, a cozinha brasileira foi influenciada desde o período colonial, quando o Brasil recebeu influências dos portugueses, africanos e dos índios. A contribuição africana se deu com o uso do coco, do azeite de dendê e da pimenta malagueta. Dos portugueses vieram o azeite de oliva, o trigo e as frutas cítricas, e dos índios (habitantes dessa terra) a mandioca, o mingau, a batata doce, o feijão, o palmito e o cacau (Freixa \& Chaves, 2012).

Para Beluzzo (2004), a cozinha brasileira é uma mistura de várias etnias de norte a sul do país, onde encontramos uma riqueza culinária com influências indígenas, portuguesas e africanas somadas às diversas outras etnias que imigraram para o país e contribuíram para a 
formação culinária local. Essas etnias formam as características peculiares de cada região do Brasil.

Assim, é impossível pensar a cozinha brasileira de forma isolada, até porque ela faz parte de uma fusão de sabores e fazeres de uma população heterogênea que desenvolveu o que contemporaneamente se tem por cozinha brasileira, como menciona Maciel (2004, p. 29):

\footnotetext{
O que se chama hoje de "cozinha brasileira" é o resultado de um processo histórico, o qual traz em si elementos das mais diversas procedências que aqui foram modificados, mesclados e adaptados. Não é possível pensar em uma "cozinha brasileira" sem pensar em uma miscigenação.
}

Logo, é comum aos comensais, durante a experimentação de novos sabores, fazer comparações da culinária local com a da sua região de origem e sentirem-se acolhidos pela nova comida. Deste modo, as cozinhas representam uma função fundamental na solidificação de laços e geram uma consciência entre as partes de uma mesma comunidade, sucedendo um intercâmbio de fronteiras entre sabores e povos.

A cozinha surge, portanto, não apenas para destacar a comida de uma determinada localidade, mas também para somar com a cozinha local e regional como forma de oferecer ao comensal uma gama de opções, na qual a comida disposta no cardápio carrega a reinterpretação ou adaptação do restaurante, conforme os ingredientes disponíveis da região, o que não causa uma descaracterização, mas sim uma unificação.

\section{CORES E SABORES DA GASTRONOMIA DE CANOA QUEBRADA}

A cozinha cearense se expressa por meio de sabores tipicamente intensos e singulares, com temperos característicos, os quais priorizam satisfazer aos mais exigentes paladares. Os pratos cearenses são compostos de marcas das manifestações da cultura regional popular e da influência herdada dos colonizadores europeus, da influência direta dos hábitos alimentares dos índios e da influência negra, marcante na região Nordeste. Deste modo, a cozinha cearense é uma mistura de sabores que se sobressaltam ao fundir essas misturas negras, europeias e, principalmente, indígenas, os primeiros moradores efetivos do Brasil. É retratada, principalmente, pelos frutos do mar, encontrados no litoral.

O foco desse estudo é a região de Aracati, localizada no litoral leste do estado do Ceará, no Nordeste brasileiro, distando aproximadamente $148,3 \mathrm{~km}$ da capital cearense, com tempo estimado de viagem de 2 horas e 7 minutos, com acesso pelas rodovias estadual CE040 e federais BR-116 e BR-304, com população estimada em 2014 de 72.248 habitantes (IBGE, 2015). 
O município de Aracati tem como atrativos o patrimônio turístico natural composto pela praia de Canoa Quebrada, que conta com uma paisagem natural, composta por dunas, falésias e lagoas, que se configuram como um forte apelo turístico; além desta, outras também compõem este cenário, como Quixaba, Majorlândia, Fontainha, Retiro Grande, Retirinho e Cumbe.

Canoa Quebrada é um destino turístico com forte vocação para o turismo de sol e praia, pelas práticas esportivas e pela cozinha composta pela variedade de frutos do mar. Para esta pesquisa, privilegiou-se os restaurantes localizados na rua chamada de Broadway, por ser a de maior movimentação.

O Restaurante A serve comida mediterrânea, uma cozinha de origem meridional, das ilhas da Sicília e Sardenha, a qual é conhecida pelos italianos como cozinha sadia, rica em carboidratos, frutas, verduras, peixes, pouca carne e muito óleo de oliva. Segundo o proprietário, optou-se por comidas que as pessoas não têm o costume de explorar em Canoa Quebrada, como o pimentão amarelo e vermelho, salsinha, vinho branco nos peixes e os caldos de peixe com fundo de verduras. As receitas são da cozinha espanhola, mas também se explora a cozinha italiana (molho de tomate e molho bolonhesa).

Todos os pratos são mediterrâneos, mesclados entre o espanhol e o italiano. Destacam-se o Frango la vino, um prato típico da Espanha, composto de alho, alecrim, salsinha, vinho branco e vinagre; Polvo à galega, polvo cozido com batata cozida, páprica doce e páprica picante; Robalo à marinera, feito à base de molho - os pescadores costumam fazer a base de tomate, pimentão, cebola, vinho branco e caldo de peixe; Suquet, um prato parecido com a panelada brasileira, sendo feito com peixe; Morcilla, linguiça com sangue do porco, algumas recheadas com cebolas ou batatas, cebola, um pouco de alho e ovo (Figura 01);Peixada mediterrânea, feita com abobrinha, abóbora, batata, pimentão, cenoura, cebola e coentro; Frango ao curry; Frango na chapa, estrogonofe entre outros.

Quando questionado sobre os pratos com ingredientes regionais, o proprietário menciona:

Eu tenho pouco ou nenhum, porque é restaurante diferenciado, aqui em Canoa todos os restaurantes seguem um padrão, o que muda é o preço e a variedade. Camarão alho e óleo e Lagosta são pratos que todos (restaurantes) fazem aqui, eu faço camarão e coloco vinho branco para ter gosto. Aqui (Canoa) as pessoas torram o camarão, aqui não (informação verbal) ${ }^{1}$.

\footnotetext{
${ }^{1}$ Entrevista concedida pelo proprietário. [Fev 2015]. Entrevistador: autora da pesquisa. Aracati, 2015. 1 arquivo
} .mp3 (19 min e 47 segundos). 
Entretanto, ao analisar o cardápio, observa-se que muitos pratos são à base de carne, como o filé mignon; frango e frutos do mar, como camarão e o peixe, portanto assemelha-se muito à cozinha regional cearense, o que diferencia é a nomenclatura do prato.

Identificou-se que poucas são as especiarias de origem internacional, somente a páprica doce e páprica picante que é trazida da Espanha e também caldo de peixe como o Knorr (caldo em cubo). Quanto às adaptações aos ingredientes regionais, o peixe robalo é um exemplo, pois não se utiliza o peixe robalo na Espanha. Utiliza-se um peixe de qualidade semelhante para as receitas. Além disso, são comuns o uso de leite de coco e o coentro.

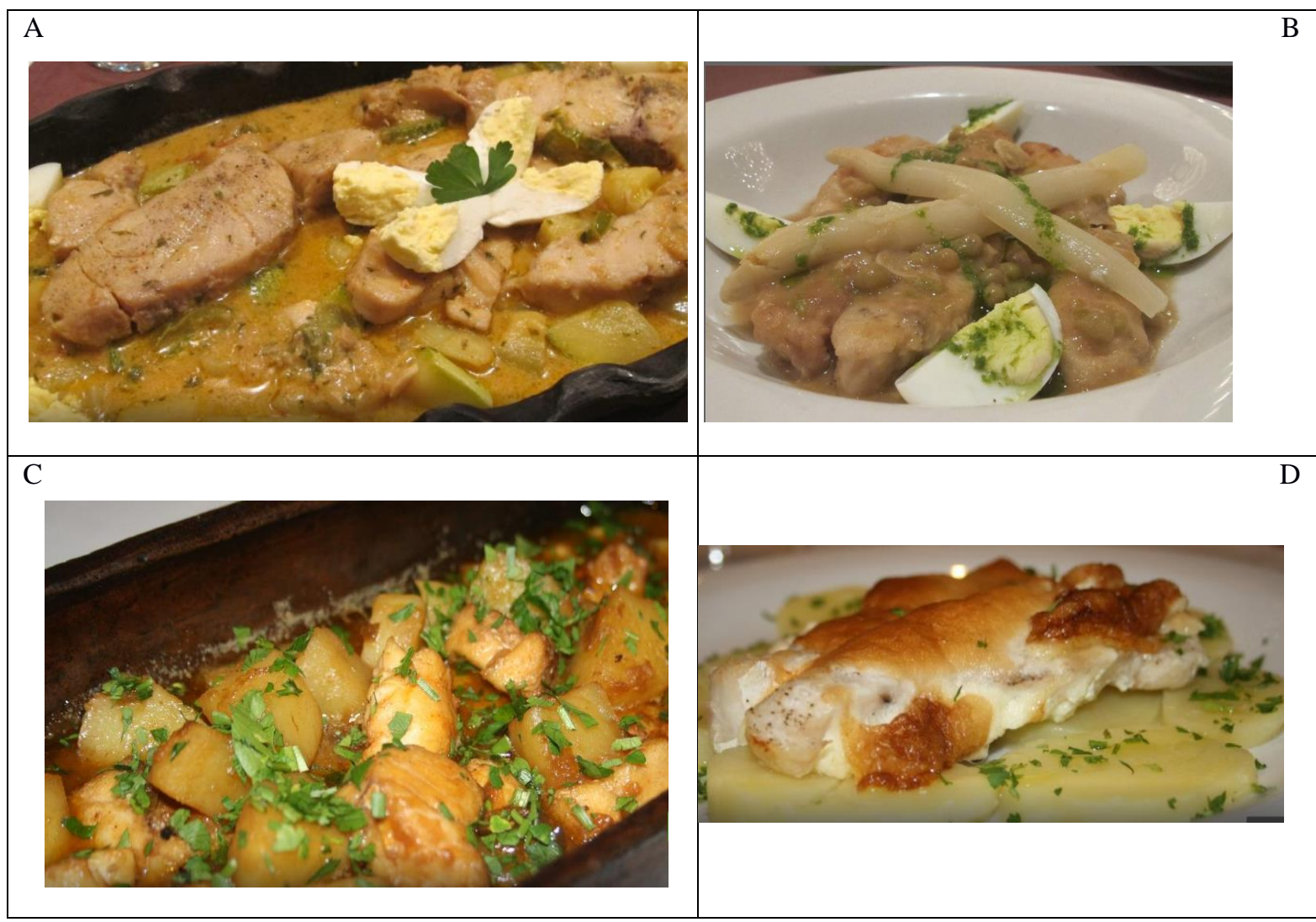

(A) Figura 01: Pratos Principais Restaurante A - (A)Peixada Medierrânea; (B) Robalo à Vasca; (C) Suquet de Frutos do Mar; (D) Robalo ao Mousse de Alho e Óleo

Fonte: Cedidas pela Gerência ao website TripAdvisor (2015)

O Restaurante B é de cozinha espanhola, e de acordo com o proprietário, quase todos os pratos são de origem internacional, sendo os mais conhecidos e pedidos: Paella de Mariscos, feita com arroz, lula, camarão e lagosta; Gazpacho Andaluz, uma sopa fria de tomate, pimentão e alho; Supremo de Robalo Real, filé de robalo assado no forno com alho, bacon e cheiro de vinagre de modena e Mariscada de lagosta, camarão e filé de robalo na chapa com arroz e salada (Figura 02).

Dentre os pratos em que se utilizam ingredientes regionais, o proprietário relata: 
Nós não produzimos comida cearense, nada de farofa, feijão, baião essas comidas, sabe. Mas, alguns pratos são praticamente iguais, pois a culinária espanhola utiliza os mesmos insumos para produção de determinadas comidas. Um exemplo é o Camarão ao alho e óleo; Camarões na chapa; Lagosta e Peixe inteiro no forno (informação verbal) ${ }^{2}$.

Quanto às adaptações aos ingredientes regionais do Ceará, o proprietário já fez uma tentativa de mesclar a cozinha internacional com a cozinha regional. Entre os anos 2006, 2007 e 2008 o restaurante participou do Sabor Brasil, criando um prato composto por Lulinhas e Feijão Branco ao Cheiro de Caju. A lulinha é muito comum na Espanha, mas o caju só é comum no Brasil, e em alguns períodos. Apesar desta experiência, o restaurante optou pelas comidas tradicionais da Espanha, visto que o proprietário tem preferência pela sua tradicional cozinha.

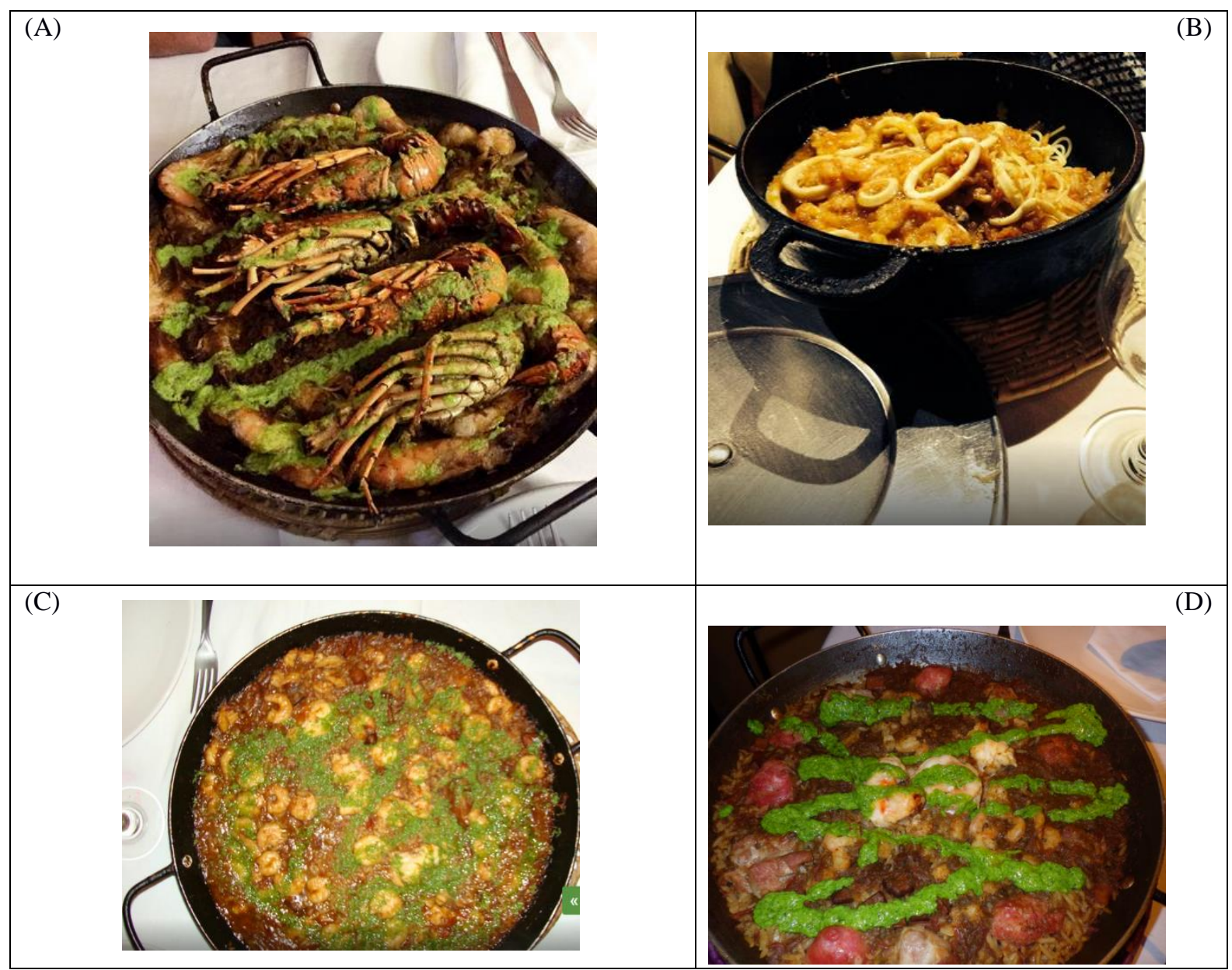

Figura 02: Pratos Principais Restaurante B - (A) Caldereta de lagosta ; (B) Spaghetti com frutos do mar; (C) Paella de mariscos;(D) Paella de cego

Fonte: Fotos dos clientes postadas no website TripAdvidor (2015).

${ }^{2}$ Entrevista concedida pelo proprietário. [Fev 2015]. Entrevistador: autora da pesquisa. Aracati, 2015. 1 arquivo .mp3 (19 min e 47 segundos). 


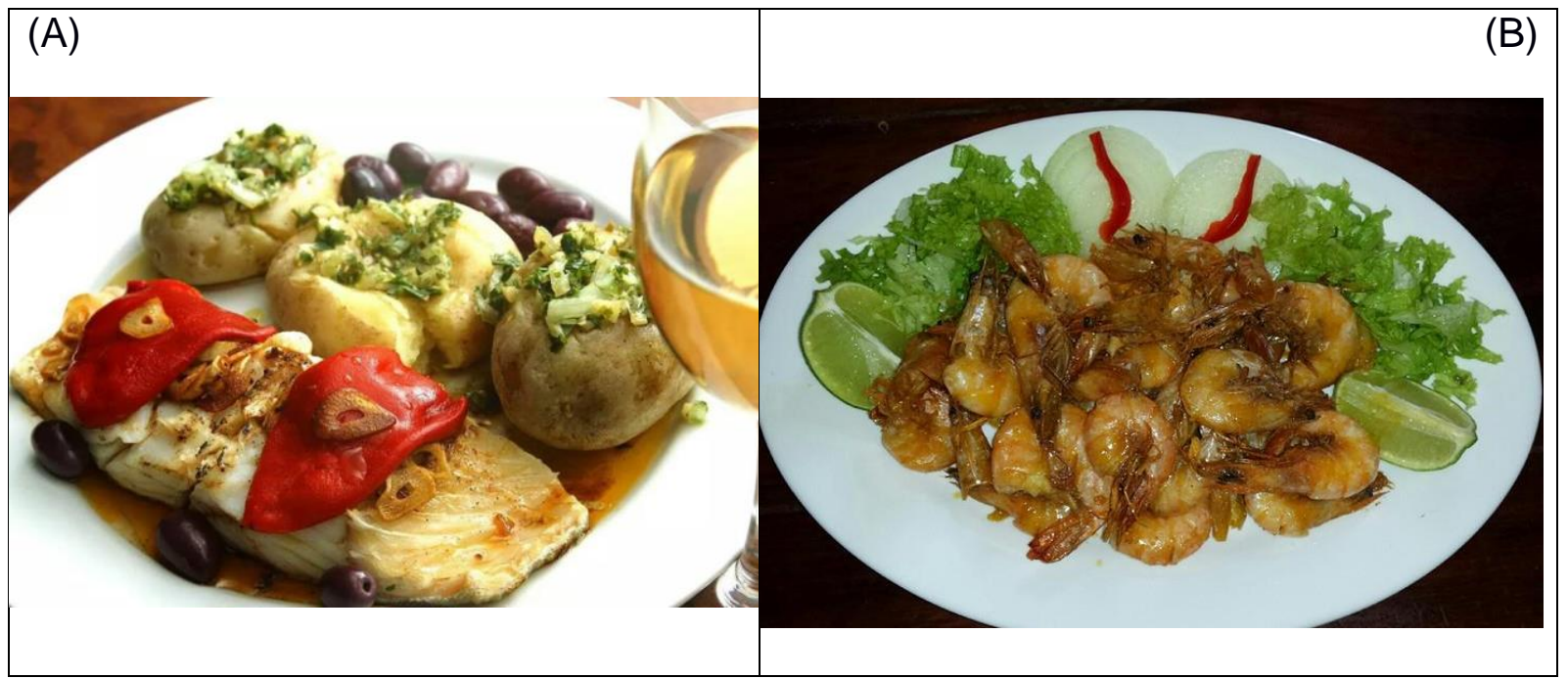

Figura 03: Pratos Principais Restaurante C - Bacalhau à Gomes de Sá IP; (B) Camarão ao alho e óleo Fonte: Fotos do facebook.com/adegadosportugueses (2015)

O Restaurante $\mathrm{C}$ é especializado na cozinha portuguesa, onde o principal prato de característica internacional é o bacalhau, em que o restaurante oferece quatro pratos à base desta proteína, envolvendo batata, cebola e creme de leite. Outros pratos também merecem destaque para a cozinha internacional como, por exemplo, a Salada de Polvo, polvo cozido com vinagrete, Bolinho de Portugal, conhecido no Brasil como bolinho de bacalhau, cujo nome usado em Portugal é na verdade croquete de bacalhau, ou pastéis de bacalhau (Figura 03). Quanto aos pratos com características da cozinha regional, destacam-se os mais conhecidos e tradicionais como a picanha, a maminha e o cupim, assim como o espaguete de camarão e espaguete de frutos do mar. "Não trabalhamos tanto com pratos daqui. Meu restaurante está mais direcionado para a cozinha internacional até por causa da estratégia na Broadway" (informação verbal) ${ }^{3}$.

Apesar de o proprietário focar os pratos na cozinha portuguesa, ficam evidentes os pratos da cozinha regional cearense. Especializado na cozinha portuguesa, os ingredientes regionais utilizados nas preparações são o cheiro verde, hortelã, pimenta do reino, o louro, o alho e a cebola. As especiarias de origem internacional são o pimentão em pó, pimenta em grão negra, o orégano (produtos trazidos da Europa). Ao ser questionado quanto às adaptações locais, como no modo de preparo, nos ingredientes, nas ervas, nas especiarias e nos temperos utilizados, o proprietário enfatiza que todos os pratos são de característica internacional e seguem a receita original. Algumas vezes os clientes pedem para fazer uma modificação nos

\footnotetext{
${ }^{3}$ Entrevista concedida pelo proprietário. [Fev 2015]. Entrevistador: autora da pesquisa. Aracati, 2015. 1 arquivo .mp3 (19 min e 47 segundos). 
pratos e são atendidos, como por exemplo, o cliente solicitar bacalhau acompanhado de arroz e feijão, mas os pratos vão à mesa com característica tipicamente de Portugal.

O Restaurante D tem como especialidade a cozinha francesa. Os pratos com características internacionais são o Blanquette de La Mer, feito com lagosta, camarão e peixe, cozido no vinho branco e limão (Figura 04). "No acompanhamento fazemos legumes cozidos, é o ratatouille que ninguém come" (informação verbal) ${ }^{4}$. Como pratos com característica regional são citados o Camarão ao Molho e Filé de Peixe ao Molho de Camarão.

Para o restaurante, não foi fácil adaptar o cardápio francês com os ingredientes locais de Canoa Quebrada, pois muitos não existem na localidade, somente na capital Fortaleza, ficando inviável essa compra em um lugar mais distante. As especiarias e temperos com características da cozinha internacional são as ervas de provence, vinho branco e tinto, molho de soja e temperos italianos que os próprios familiares trazem da França.

O prato adaptado à cozinha regional foi a feijoada francesa, uma carne cozida no vinho tinto, um prato bem típico francês que teve que ser adaptado, mas na maioria, é possível adaptar o cardápio com os ingredientes locais.

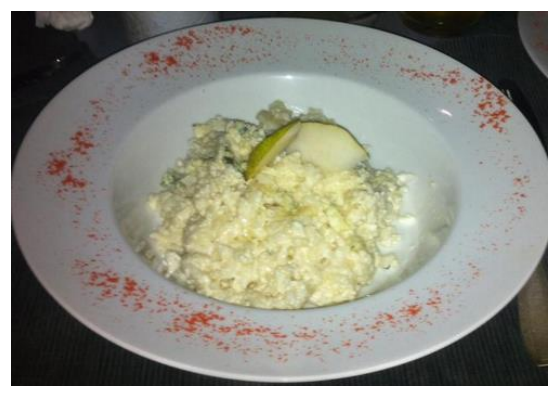

Figura 04 - Risoto de pera com gorgonzola

Fonte: Fotos do website TripAdvidor (2015).

O Restaurante E retrata a cozinha mediterrânea, principalmente pratos italianos, em que o proprietário frisa a cozinha italiana e brasileira como semelhantes. Apresenta como pratos internacionais massas frescas feitas à mão (Figura 05), como o Talharim de frutos do mar, além do Carpaccio de peixe e Carpaccio de carne. Quanto aos pratos de características regionais, o proprietário é enfático ao responder que "não tem comida regional aqui. Temos pratos brasileiros como a picanha, maminha, essas carnes. Trabalhamos com camarão ao alho e óleo, lagosta também" (informação verbal) ${ }^{5}$.

\footnotetext{
${ }^{4}$ Entrevista concedida pela proprietária. [Fev 2015]. Entrevistador: autora da pesquisa. Aracati, 2015. 1 arquivo . $\mathrm{mp3}$ (11 min e 55 segundos).

${ }^{5}$ Entrevista concedida pelo proprietário. [Fev 2015]. Entrevistador: autora da pesquisa. Aracati, 2015. 1 arquivo .mp3 (14 min e 42 segundos).
} 


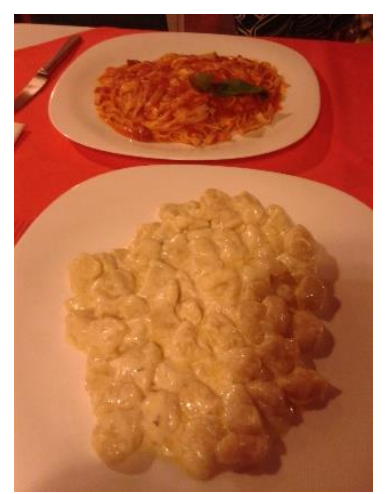

Figura 05: Massas no Restaurante E Fonte: Pesquisa direta, (2015).

Os pratos característicos do restaurante são como destaque as massas, que são preparadas pelo próprio chef italiano, onde o cliente pode escolher entre talharim, ravióli e nhoque e, a partir disso, indicar o molho que mais lhe agrada, entre os quais evidenciam-se: carbonara, feito com bacon; alho e azeite; tomate basílico, feito com alho, tomate, cebola e manjericão; pesto genovese, característico de Genova, na Itália, preparado com alho, manjericão italiano de folha larga, queijo, azeite e pinoli, semente que lembra amêndoa, mas no Brasil a receita pode ser substituída por castanha do Pará e o molho sorrentina, tomate sem pele e manjericão de folha larga.

\section{CONSIDERAÇÕES FINAIS}

A partir da análise dos cardápios dos restaurantes internacionais de Canoa Quebrada, conclui-se que estes revelaram a autêntica cozinha internacional, admitindo-se a combinação com ingredientes regionais do Ceará. Os pratos ofertados no cardápio são de fato tipicamente internacionais, embora alguns bem semelhantes com a cozinha regional, já que boa parte da matéria prima se relaciona com os peixes e frutos do mar da costa cearense.

Destacam-se pratos tipicamente internacionais como a famosa e conhecida paella, um prato Espanhol; o bacalhau de Portugal; os risotos e carnes francesas e as massas e carpaccio italiano. Identificou-se, ainda, os pratos tipicamente internacionais com ingredientes ou adaptações regionais, como a utilização do peixe robalo e o uso de ervas, temperos e especiarias como o leite de coco, coentro e cheiro verde.

Os restaurantes apresentaram pratos típicos dos seus países, no entanto, a diferença está na nomenclatura dos pratos. Percebeu-se que não se tratam de misturas de ingredientes entre uma cozinha e outra, o que se sobressai são suas origens. As proteínas utilizadas na 
elaboração dos pratos constituem-se na sua essencialidade em camarão, peixes, lagosta e outros frutos do mar.

Constatou-se que são utilizadas técnicas diferenciadas, novas leituras para o preparo de determinados pratos do cardápio, permuta de ingredientes, agregando a ela adaptações de um lugar para outro, colaborando com as cores, sabores, temperos, história e cultura. Porém, nada que descaracterize a cozinha internacional.

Assim, convém refletir acerca do regionalismo presente no prato, representado pelos ingredientes regionais e locais, não só como uma preocupação do espaço gastronômico, mas como uma representação para a cultura e para a comunidade de Canoa Quebrada, uma vez que é totalmente aceitável um restaurante conceber pratos internacionais com características regionais cearenses. Todavia, a cultura local tem desaparecido frente aos empreendimentos de alimentação com características internacionais, trazidas pelos proprietários estrangeiros. Logo, para estudos futuros, pode-se refletir sobre a questão das raízes culturais em relação à cozinha local, como forma de manter preservada a cozinha local cearense.

\section{REFERÊNCIAS}

Arana, G. N. (2012). Los Espacios de La Cocina Mexicana Al Albor del Siglo XX. La creación alquímica de olores, sabores y texturas. Bogotá: Apuntes.

Bahl, M., Gimenes, M. H. S. G., \& Niestche, L. B. (2011). Territorialidade gastronômica: as cozinhas regionais como forma de mediação do homem com o meio e como atrativo turístico. Revista Geográfica de América Central (online), 2, 1-16.

Beluzzo, R. A. (2004). Valorização da Cozinha Regional. In: I Congresso Brasileiro em segurança alimentar. Brasília.

Botelho, A. (2012). Geografia dos sabores: Ensaio sobre a dinâmica da cozinha brasileira. In: Revista Textos do Brasil - Sabores do Brasil, 3.

Canadian Tourism Commission. (2002). Acquiring a Taste for Cuisine Tourism: a product development strategy. Ottawa: Canadian Tourism Commission.

Casanova, I. (1996). A força ilocutória dos actos directivos. In: FARIA, I. H et al. Introdução à Linguística Geral e Portuguesa. Lisboa, Editorial Caminho.

Castelli, G. (2003). Administração Hoteleira. São Paulo: Saraiva.

Ceará, Governo do Estado. (2016). Indicadores Turísticos 1995/2015. Fortaleza: Setur.

Dencker, A. F. M. (1998). Pesquisa em turismo: planejamento, métodos e técnicas. São Paulo: Futura.

Franco, A. (2004). De caçador a gourmet: uma história da gastronomia. São Paulo: Senac. 
Freixa, D. \& Chaves, G. (2012). Gastronomia no Brasil e no Mundo. Rio de Janeiro: Senac Nacional.

Galvão, R. (2006). Aracati: labirintos de sonho e luz. Fortaleza: Sebrae.

Gerdes Filho, R. \& Lopes, J. D. S. (2009). Curso de cozinha Internacional: parte I. Viçosa, MG: CPT.

IBGE. Ceará - Aracati. (2015). Recuperado em 9 de fevereiro, 2015, de http://cidades.ibge.gov.br/xtras/perfil.php?codmun=230110

Kivela, J. \& Crotts, J. (2006). Tourism and gastronomy: Gastronomy's influence on how tourists experience a destination. Journal of Hospitality and Tourism Research, 30(3), 354377.

Lakatos, E. M. \& Marconi, M. A. de. (2008). Metodologia Científica. (5a ed., 2a reimp.) São Paulo: Atlas.

Maciel, M. E. (2004). Uma Cozinha à Brasileira. Estudos Históricos, Rio de Janeiro.

Mendonça, J. R., Barbosa, M. L. A. \& Durão, A. F. (2007). Fotografias como um recurso de Pesquisa em Marketing: o uso de métodos visuais no estudo de organizações de serviços. Revista de Administração Contemporânea, 11(3), jul./set.

Montanari, M. Comida como cultura. (2008). São Paulo: editora Senac.

Montebello, N. de P. \& Collaço, J. H. L. (2007). Gastronomia: cortes e recortes (2a ed.) Brasília: Senac.

Murta, I. B. D., Souza, M. M. P. de \& Carrieri, A. de P. (2010). Práticas discursivas na construção de uma gastronomia polifônica. RAM - Revista de Administração Mackenzie, $11(1)$.

Pacheco, A. de O. (2005). Manual do Maître d'Hôtel. (5a ed.). São Paulo: Senac SP.

Reinhardt, J. C. (2002). O pão nosso de cada dia - a Padaria América e o pão das gerações curitibanas. Curitiba. Dissertação (Mestrado em História) - Setor de Ciências Humanas, Letras e Artes, Universidade Federal do Paraná.

Santich, B. (2004). The Study of Gastronomy and its Relevance to Hospitality Education and Training. International Journal of Hospitality Management.

Schlüter, R. G. (2003). Gastronomia e turismo. São Paulo: Aleph.

Spang, R. L. (2003). A Invenção do Restaurante. Rio de Janeiro: Record.

Tripadvisor. (2014). Melhores Restaurantes em Canoa Quebrada. Recuperado em 1 de junho, 2014, de http://www.tripadvisor.com.br/Restaurantsg635974Canoa_Quebrada_State_of_Ceara.html Vasconcellos, F., Cavalcanti, E. \& Barbosa L. (2002). Menu: como montar um cardápio eficiente. São Paulo: Roca. 